\title{
Carta a un joven cruzado
}

\section{Liliana Pérez Recio ${ }^{1}$}

Submetido em: 04/07/2020

Aprovado em: 12/11/2020

DOI: $10.5965 / 23580925242020214$

1 Doutoranda em Teatro na Universidade do Estado de Santa Catarina (UDESC). Diretora

Teatral e Atriz. E-mail: bastianybastiane@gmail.com 


\section{RESUMEN}

Esta misiva junta algunas memorias y reflexiones en relación a la edición número XXX de la Cruzada Teatral Guantánamo-Baracoa. Esta ocurre en la provincia más oriental de Cuba, organizada por los grupos de teatro de la región con el apoyo de las instituciones locales. Varias agrupaciones teatrales, nacionales y extranjeras, parten por caminos intrincados y acampan, de pueblo en pueblo, para llevar teatro a las comunidades aisladas de la serranía guantanamera, una vez por año. Sobre los orígenes, las estrategias y significados de este evento reflexiono, en condición de novel participante, teniendo como interlocutor a un joven de la segunda generación de artistas que protagonizan el futuro del teatro en las comunidades aisladas entre el mar y la montaña.

Palabras claves: cruzada teatral, Guantánamo, comunidad.

\section{ABSTRACT}

This letter brings together some memories and reflections on the XXX edition of the Guantánamo-Baracoa Theater Crusade, which takes place in the most eastern province of Cuba, organized by theater groups in the region with the support of local institutions. Several theater groups, national and foreign, set out on intricate paths and camp from village to village, to bring theater to isolated communities in the Guantánamo Mountains once a year. On the origins, strategies and meanings of this event, I am reflecting, as a new participant, having as a partner a young man of the second generation of artists who support the future of theater in isolated communities between the sea and the mountains.

Keywords: theatrical crusade, Guantánamo, community. 
El resultado de su procedimiento consiste en que en la obra queda conservada y superada la obra de una vida, como en la obra de una vida una época, y en la época el decurso de la historia.

(Walter Benjamín)

\section{FLORIANÓPOLIS, 17 DE FEBRERO DE 2020.}

\section{Compadre Yosmel2,}

¿Cómo le va de regreso al camión? ¿Qué tal sus alumnos? Nosotros bajamos el cuerpo, pero el alma se nos quedó enredada en algún patio de escuela.

Dicen que no hay tiempos fijos, que a todos nos llegan los eventos en el momento justo. Hay quien pare viejo, hay quien va a la escuela de noche, hay quien se enamora en el círculo de los abuelos, hay quien llega a la Cruzada teatral Guantánamo Baracoa $^{3}$ con diez años, o con cuarenta. Esa soy yo y lo asumo

2 Yosmel López Ortiz (1990) pertenece a la segunda generación de cruzados. Vicepresidente de la Asociación Hermanos Saíz en la provincia de Guantánamo. Estudió en la Escuela Profesional de Arte Manuel Muñoz Cedeño de Bayamo, Granma. Es actor titiritero, directores artísticos en el grupo donde creció, Teatro Guiñol de Guantánamo. Este, arribó en el año 2020 al cincuenta aniversario de su fundación, cuando se constituyó como la primera agrupación profesional de las Artes Escénicas en la provincia el 4 de abril de 1970.

3 La Cruzada, Premio Nacional de Cultura Comunitaria, la encabezan los conjuntos guantanameros Guiñol, La Barca y Ríos. A principios de la década de 1990, con la grave situación económica que atravesó Cuba, la carencia de recursos imposibilitaba mantener un nivel de trabajo cultural estable en la provincia de Guantánamo que atendiera a la población rural. Era necesario encontrar respuestas creadoras, la programación se tornaba un tanto monótona como resultado de la carencia de espacios y otros elementos. Entonces, surge en el seno del grupo de Teatro Guiñol, que en aquel momento se nombraba Esopo, la idea de recorrer parte de las serranías guantanameras llevando el teatro a las zonas de difícil acceso y de silencio. En alrededor de 35 días, recorriendo los municipios de Manuel Tames, Yateras, San Antonio del Sur, Imías, Maisí y Baracoa se realizan un promedio de 200 funciones. Algunas presentaciones se producen en el camino, otras requieren salidas a caballo, en carretas, en tractores, etc. Además, se ofrecen funciones nocturnas en la comunidad donde se duerme. (In: Diseño de la xxx cruzada teatral Guantánamo Baracoa. Consejo Provincial de las Artes Escénicas. Dirección Provincial de Cultura. Poder Popular Guantánamo). 
con la certeza de que, como en el amor, se precisan las condiciones favorables para transitarla. Me hicieron falta veinte años de trabajo, casi nada, para llegar a Guantánamo con el respeto y la humildad que se requiere. Traigo la experiencia de las BETARTE organizadas por Norma Mederos ${ }^{4}$ al frente de la vice-rectoría de extensión universitaria, en el Instituto Superior de Arte (19972000). Esas salidas al campo me han determinado hasta hoy: Ciénaga de Zapata junto al proyecto comunitario Korimakao (1992) y desde Chibirico hasta El Uvero conociendo el proyecto La Bruja. En realidad, la primera salida fue a Moa con el apoyo de su filial universitaria. Todos esos viajes nos pusieron a Cuba en frente y al cuerpo en la escena real, con público real. Desde entonces, recordando las misiones culturales de Raúl Roa en la década de 1950 que también determinaron la vocación del naciente Guiñol de Cuba, entiendo que es de una importancia capital que los estudiantes de arte tengan esa experiencia extramuros a fin de sensibilizarse con el público que los espera, con la realidad como interlocutora. Dos décadas después, vuelvo a la montaña con las provocaciones de mis profesores de posgrado en la Universidad del Estado de Santa Catarina, Brasil. Busco, más allá del circuito capitalino de la calle Línea, un teatro necesario. 


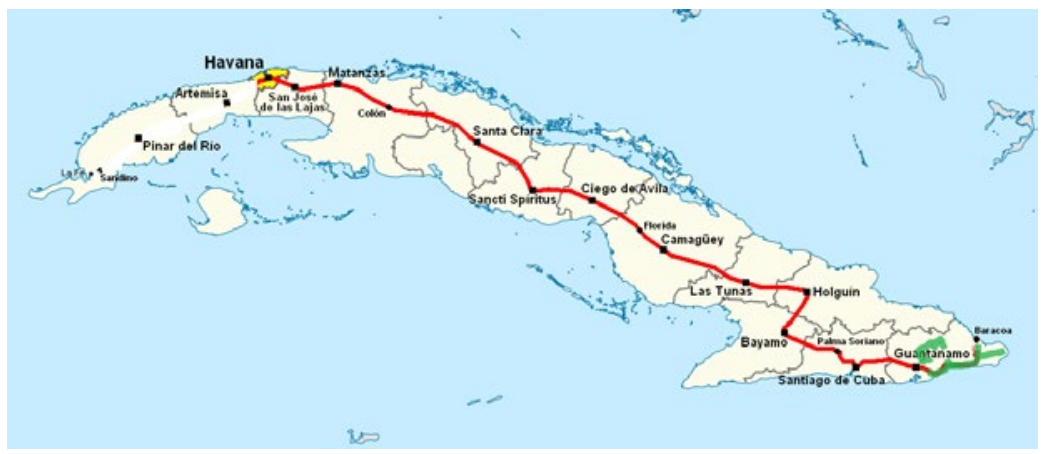

Figura 1: Desde la Capital hasta Guantánamo 18 horas por carretera, enero de 2020. El bloqueo económico del gobierno de los Estados Unidos contra Cuba deja el país sin abastecimiento de combustible. Se cancelan vuelos nacionales. Las autoridades locales se debaten para no suspender la Cruzada.

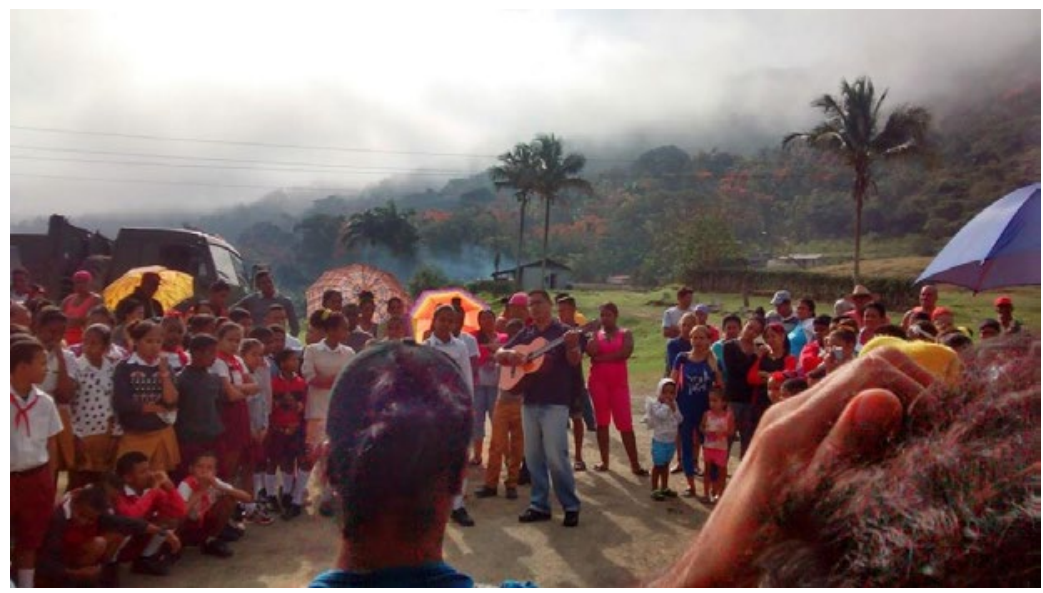

Figura 2: Recibimiento a la Cruzada por los artistas aficionados locales, La Alegría, Yateras.

Fuente: Foto del autor (2019) 
Ahora que la sangre está caliente le escribo. Cosa que casi nunca el pudor me permite puesto que siempre me siento desautorizada, pero, como me ha invitado y porque ya sabemos en la piel eso de que subir lomas nos hermana: sea mi carta como una confesión de noche estrellada en la manigua, cuando la emoción desborda y nos sinceramos. Sirva esta para iniciar un diálogo donde crucemos hablas y escuchas, y su experiencia tire un cable a tierra a mi entusiasmo.

La Cruzada es, a mi modo de ver, un Acontecimiento $^{5}$, que se realiza en muchos planos convergentes: nuestras vidas, nuestra obra, las comunidades y entre ellas la comunidad artística guantanamera, las instituciones, el Guiñol Guantánamo, la Nación, la Tierra. En ella, el tiempo se suspende y se dilata. En el rincón donde se echa el cruzado, no cuentan otras referencias que el siguiente destino y la llamada de la próxima comida. Las energías se potencian y un paréntesis se instala con la irrupción de una turba de extraños con sus músicas y su aspecto estrafalario de andariegos foráneos.

No median en este encuentro grandes pactos, no se ha fijado un con/trato entre el campamento y la comunidad ${ }^{6}$. Al respecto me hacen reflexionar los relatos de los fundadores; como cuando escucho a Maribel López relatar: “Nunca acampamos en la comunidad, no queríamos que nos vieran como interventores, queríamos que nos vieran como amigos, como gente tan humilde como ellos. Compartían el café con nosotros, y le correspondíamos compartiendo nuestra comida" (GARBEY, 2018, n. p.). A su manera, Rafael Rodríguez siempre cuenta:

El Guiñol ya había recorrido las montañas, y con la Cruzada abarcaríamos mucho más. Es verdad que no habían recursos como ahora, pero con el apoyo de las Fuerzas Armadas Revoluciona-

5 Benjamín, Walter. Una oportunidad revolucionaria. In: Sobre el concepto de historia. Obras I, 2, pp. 316-317.

6 Me he hecho preguntas al respecto del cuidado del entorno y la actitud de los cruzados en el campamento, una suerte de reglamento interno que no lleve al límite esa irrupción en el cotidiano. Es sorprendente cuánta basura puede juntar un día de campamento, por ejemplo. Me cuestiono una ética del cruzado en términos de sostenibilidad no invasiva. 
rias obtuvimos lo necesario para la vida en campaña: hamacas, colchas, mosquiteros, y hasta palas [...]. Nos dieron un mapa y trazamos la ruta. [...] Era 23 de septiembre cuando surge la idea, y Bonaga propuso salir el 28 de enero en homenaje a José Martí. Desde el parque central partimos con los mulos cargados de utensilios, a pie a las 6:00 pm y nos cogió la noche. Fuimos a Argeo Martínez y la primera función fue en el campamento de cañeros con Pepín el Burrito y El Fotuto, comedias de Las mil y una noche guajiras, del camagüeyano Rómulo Loredo. (MARTíNEZ, 2020, n. p.)

Sucedidas treinta cruzadas, somos recibidos con afecto y gratitud. Ahora -en un arduo esfuerzo de organización que solo es posible con la participación de los gobiernos locales- las escuelas, las casas de cultura, los policlínicos ofrecen albergue a la itinerante tropa de teatreros. De repente le nacen a la comunidad coloridas casas de campaña, súbitas tendederas y una cocina improvisada. A propósito de esa irrupción en el cotidiano de las montañas, ya esperada cada año en fecha fija como quien espera la cabalgata de los reyes magos, quisiera enfatizar mi opinión invitando a la lectura de los trabajos del profesor Kinceler (1960-2015), quien en su pasión por el arte como relación afirmó:

\begin{abstract}
Entendemos que para actuar fuera de la zona de confort, en la que conscientemente somos seducidos a permanecer, el proceso creativo exige formas que produzcan acontecimientos, transformaciones. Reconociendo que el venir a ser ocurre cuando una imagen mental es producida por experiencias vitales que tocan la realidad, el juego representacional del arte contemporáneo en su forma colaborativa va a buscar otras formas para re-articular las complejas relaciones entre el proponente y la propuesta de un público que necesita ser reinventado e involucrado como acontecimiento. (KINCELER, 2016, p. 243-244, traducción mía7)
\end{abstract}

7 Entendemos que para atuar fora da zona de conforto, na qual conscientemente somos seduzidos a permanecer, o processo criativo exige formas que produzam acontecimentos, devires. Reconhecendo que o vir a ser ocorre quando uma imagem mental é produzida por experiências vitais que tocam o real, o jogo representacional da arte contemporânea em sua forma colaborativa vai buscar outras formas para rearticular as complexas relações entre o propositor e a 
Es por eso que estoy convencida de que en este cruce los que más aprenden son los cruzados. Venimos al encuentro de vidas, de sabores, de tiempos diversos. La comunidad se nos revela, en efecto, como el raudal de la vida y su cultura. En la complejidad de la globalización, allí donde ya llega internet, distinguimos la experiencia glocal ${ }^{8}$. Apropósito del término podría citar esta definición:

En este sentido, el Glocal para el antropólogo involucra el campo de la cultura, generando dos movimientos opuestos. El primero es el movimiento de globalización, en el que aparece una red planetaria de procesos industriales, tecnológicos y culturales, entre otras características, que cuestiona sujetos diferentes, en dimensiones espaciales diversas, a través de bienes simbólicos. El suministro de tales bienes se muestra homogeneizador de hábitos de consumo a medida que ignora fronteras geográficas, atrayendo diferentes segmentos de consumidores. Paralelo a este movimiento globalizador, existe el movimiento de localización de la cultura. En este caso, se retoman las tradiciones locales en un proceso de búsqueda de rasgos culturales capaces de marcar la diferencia entre los pueblos y su pertenencia, a sus territorios de origen. (DOS SANTOS; NOLASCO, 2010, p.72, traducción mía9)

proposta de um público que necessita ser reinventado e envolvido como acontecimento.

8 Aunque no siempre es fácil fechar el origen de los conceptos, actualmente se acepta que la primera referencia al término glocalización aparece en la década de 1980, siendo consagrada en El Oxford Dictionary of New Words, que se refiere al proceso de "telescopios globales y locales hacer una mezcla". El concepto fue inicialmente construido a partir de la palabra japonesa dochakuka que originalmente se refería a la adaptación de nuevas técnicas agrícolas a las condiciones de producción local. Rápidamente adoptado y popularizado en el mundo de negocio, su significado más común se refiere a un producto o servicio diseñado y distribuido globalmente, pero adaptado a los hábitos y costumbres locales. (LOURENÇO, 2014, p. 2, traducción mía)

90 Glocal para o antropólogo envolve, nesse sentido, o campo da cultura gerando dois movimentos contrapostos. O primeiro deles é o movimento de globalização, no qual surge uma rede planetária de processos industriais, tecnológicos e culturais, entre outras características, que interpela sujeitos diferentes, em dimensões espaciais diversas, através de bens simbólicos. A oferta de tais bens se mostra homogeneizadora de hábitos de consumo à medida que ignora fronteiras geográficas, atraindo diferentes segmentos consumidores. Paralelo a esse movimento globalizador, surge o movimento de localização da cultura. Neste caso, ocorre uma retomada das tradições locais, num processo de busca por traços culturais capazes de marcar a diferença 
De tal forma que el Chagüí10, la cocina guantanamera, sus voces y los saberes de la tierra, constituyen la fuerza de su gente y en ellos se verifican. Glocalmente, se destaca ante mis ojos el modo en que las escuelas, por más remota que estén, cuenta con los mismos recursos y medios didácticos dispuestos por igual a lo largo del país para todos los centros de enseñanza. Estas y otras tantas realidades saltan a la vista del cruzado en muy legítimo trueque. En él, constatamos, para el asombro de Sérgio Silva el fotógrafo paulista, como todos los niños lucen medias y zapatos, cintas peinan las niñas y las pañoletas ondean la bienvenida. Entonces uno cae en cuenta de que para Sérgio no tener zapatos es una realidad cotidiana, que lo extraordinario es tenerlos y que podrían no estar más allí.

Aunque muchas dificultades de orden administrativo aquejan a las comunidades ${ }^{11}$, en ellas nos reciben actores, cantan-

entre os povos e o pertencimento destes, a seus territórios de origem.

10 Changüí y Son están emparentados por la misma línea familiar del complejo sonoro del Caribe. En la música tradicional guantanamera existen otras expresiones consideradas células primigenias del Son: los nengones, el Kiribá y otros soncitos provenientes de la antigua región de Baracoa, que incluía a Imías, San Antonio del Sur y Maisí. Estos poseen elementos comunes en los que predominan instrumentos como el tres, el bongó, la marímbula, el guayo o el güiro y las maracas, algunos de los cuales son atribuidos a una influencia de origen Bantú. Significativo es el uso del guayo característico del Changüí, hecho de una plancha de metal perforada, semejante al usado para rayar el coco y la yuca, cultivos básicos de la culinaria de la región. En las canturías se destaca el uso de la cuarteta y la décima para la improvisación. El Chagüí del monte se toca más lento. Se asociaba a las festividades desde navidad hasta día de Reyes, pasando de casa en casa y danzado bajo una enramada de guano con piso de tierra. El bailador sacaba su pañuelo y se lo ponía al hombro, la muchacha que se adueñara de este bailaba con él. Pasó de la zona rural a la periferia de la ciudad. El género, transitando por varias etapas, tiene protagonismo en el imaginario popular guantanamero. En su evolución ha tenido un papel importante la participación de las mujeres, las que se destacan como bailadoras, músicos, cocineras, promotoras y anfitrionas. Para profundizar el tema, sugiero ver ESTONEL LAMOTH, Yaremi. Guantánamo tiene su Changüí. Guantánamo, El Mar y la Montaña, 2018.

11 Sobre todo, en lo que respecta al estado de los caminos y los medios de transporte, así como los abastecimientos. Asuntos que exigen atención inmediata de parte de los órganos de administración. Inclusive se hace urgente una reflexión sobre cuánto el estado de las vías repercute en la eficiencia económica, también un análisis de cómo las riquezas producidas en el territorio retornan a los presupuestos locales. Sobre las provincias orientales propongo leer ÍNIIGUEZ ROJAS, Luisa. Oriente por dentro, miradas a su heterogeneidad 
tes, bailadores aficionados en formación que, en la mayoría de los casos, cuentan con un instructor o un promotor cultural que asume el compromiso con el futuro y la continuidad del patrimonio local. Así lo registran los investigadores que acompañan la Cruzada, como lo expresa Isabel Cristina:

Además de un público entrenado y culto, la experiencia de casi tres décadas de intercambio ha generado un movimiento importante en torno al arte y el teatro en la montaña. [...] Muchos niños que vieron la Cruzada durante su infancia luego estudiaron en las escuelas de Instructores de Arte. Es por eso que Guantánamo va a la vanguardia de las provincias con mayor número de instructores en todo el país. Hoy, algunos de ellos son los que lideran proyectos socioculturales en las comunidades más intrincadas. Mientras los cruzados pasan una vez al año en La Clarita se queda el Teatro Campesino Monteverde; en Chafarinas, el Proyecto Arcoíris; en Yateras, El Amor Toca a tu Puerta; y en Palma Clara, La Flor del Café. Y así, en otros sitios de la montaña, van quedando los hijos de la Cruzada, nacidos del trabajo de los instructores de arte y los promotores culturales, quienes se encargan de ejercitar la alegría y enseñar a los niños el changüí, el nengón, la puntillita y el quiribá. (LÓPEZ HAMZE, 2019, n. p.)

Junto con eso, todo mezclado, encontramos expresiones ya no tan felices que deberían alertar los diagnósticos, partes de una verdad glocal. A su vez, la permeabilidad de la cultura se constata cuando encontramos en San André de Yateras un grupo de adolescentes que cultivan Kizomba angolana y refieren autores de la provincia. Nótese que el surgimiento de este género contiene influencias caribeñas. La cultura respira por caminos insondables, indetenible como las aguas, se nutre y reconfigura en un ciclo infinito.

territorial. La Habana, UH, 2017. p. 21, donde se relata el desigual desarrollo social del oriente cubano. 


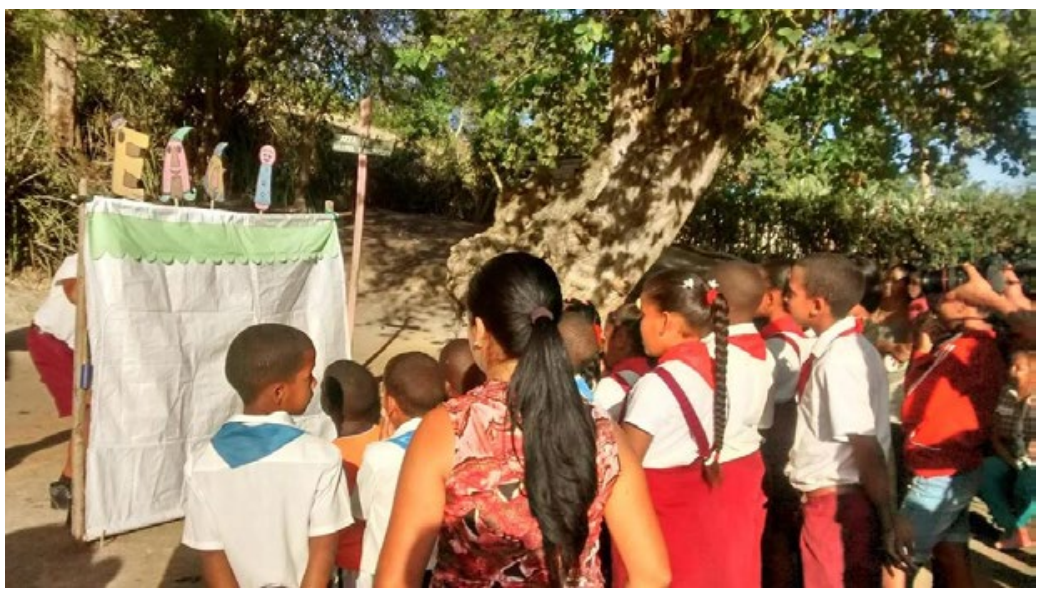

Figura 3: En El Silencio, Felicidad de Yateras, los niños de la Escuela esperan a los cruzados con sus obras de teatro

Fuente: Foto del autor

Retomemos la idea del diagnóstico. Adentrarse en la serranía es una oportunidad sin comparación para las instituciones. Tanto es así que nos ha acompañado este año en la XXX edición de la Cruzada un compañero de la dirección de patrimonio de Guantánamo para poder visitar, aprovechando la infraestructura de la Cruzada, sitios patrimoniales que por remotos poco o nunca reciben atención. Igualmente, los fotógrafos que acompañan son autores de un registro único sobre el devenir regional. Este es apenas un ejemplo de cómo el paso de la Cruzada viene permitiendo el acceso al conocimiento de estas realidades en sus particularidades. Conversamos con el médico de guardia, corroboramos que problemas sociales como el alcoholismo y el embarazo precoz subsisten.

Es aquí que me pregunto, cómo la Cruzada retorna año tras año y responde a este conocimiento. De qué forma los grupos locales, los invitados, la curaduría de la Cruzada integra este deber de dialogar, polemizar en comunidad más allá de la experiencia entretenida. Al respecto, recuerdo cómo un espectáculo 
invitado el año pasado, Sangría de Brasil, levantó la polémica al traer al ruedo el asunto del machismo. Sapinchik, de Perú, ha establecido una gran identificación con el público guantanamero al abordar la condición del emigrante a las ciudades, los que portan sus identidades culturales en resistencia para una defensa de la diversidad como derecho a ser mundo. Este y otros ejemplos demuestran como el Acontecimiento en que se constituye la Cruzada ofrece al público guantanamero el privilegio de dialogar con estéticas tan diversas; con temas que les son urgentes y que tal vez de la mano de los grupos nacionales no se levantarían, puesto que como hemos visto el asunto opera en la dimensión Glocal.

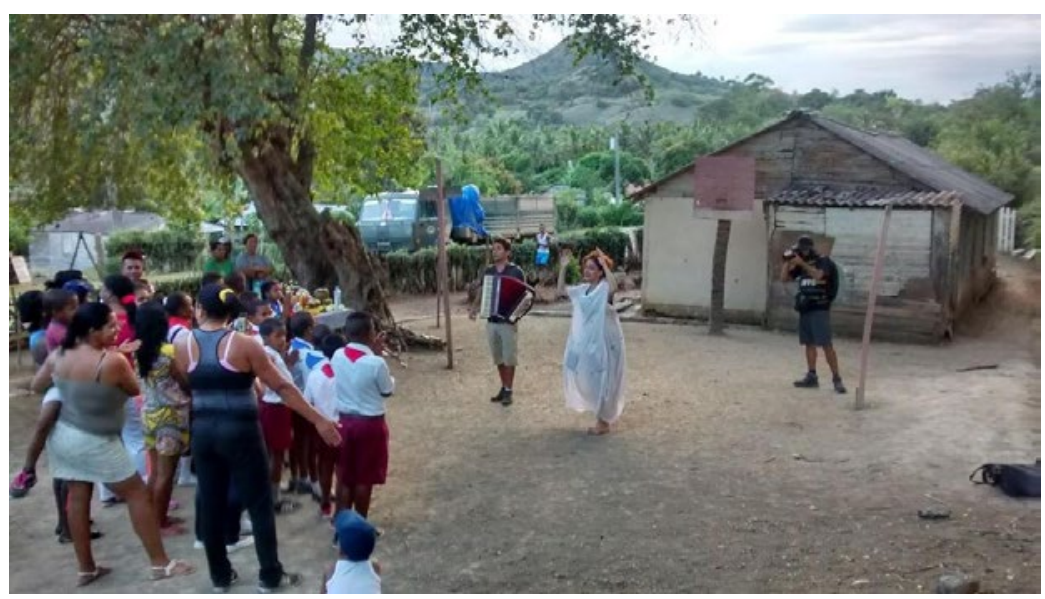

Figura 4: Sangría, de Brasil, se presenta en Yateras para hablar de siglos de atropellos al derecho de las mujeres. Al fondo, a la izquierda, el camión de la Cruzada. En él, más de veinte artistas cruza montañas, desiertos y caminos enfangados, no sin peligros. A la derecha, la escuela. Pilar, la delegada, me dijo esperanzada que este año sí le aprobaron el presupuesto para hacerla nueva.

Fuente: Foto del autor. 
De esta forma, el trueque se produce también al interior de la organización. La Cruzada es un gran caldo del que no se sale indemne. En la convivencia nos vemos los unos a los otros los espectáculos, trocamos ideas y confirmamos que tenemos mucho en común, que no estamos tan solo. Técnicas, entrenamientos, libros, todo se cruza; de tal suerte que al bajar usted siente, en efecto, que ha pasado un curso riquísimo y singular. Con este objetivo un esquema de acciones se ha ido estableciendo a lo largo de los años, fijando pequeños eventos dentro de la programación por municipios. Pasemos revista. En Manuel Tames, lleva por título Construyendo espacios culturales para la vida, que no es más que la oportunidad de convivencia con los proyectos artísticos La Colmenita Guantanamera y el proyecto sociocultural Jagüey La esperanza. ¡Cómo me conmueve esa biblioteca comunitaria y ese poeta que cuida de la librería del batey! Después, para Yateras se sueña Un laboratorio teatral para todos, que es donde tenemos la oportunidad de disfrutar, en su propio territorio, de el Teatro campesino Monte verde, el grupo teatral Lino Álvarez de Las Mercedes. ¡Qué sorpresa maravillosa encontrar esa familia de teatreros, familia de verdad, que trasmite el amor por el teatro a más de tres generaciones! Y como de movimiento de teatro de aficionados se trata, pues es donde se aprovecha para integrar la Brigada José Martín ${ }^{12}$, con la posibilidad de enviar propuestas de todo el país. Al llegar a San Antonio del Sur, dadas las características urbanas de la cabecera municipal, se propone, Un escenario callejero para imaginar el teatro, con el propósito de estimular el trabajo de los instructores y aficionados para la realización del evento TEACALLE; cada jornada culmina en la noche con una intervención colectiva y callejera. Le siguen las noches de Imías con la gran contada, Pá la oreja un cuento o un cuento Pá la oreja, con lo que se potencia el alcance social de la Narración Oral Escénica. Una vez más el Changüí, la inclusión social de los discapacitados y la nueva generación de instructores de arte.

12 La Brigada José Martí (2004), es un movimiento cultural que tiene como escenarios fundamentales, aunque no únicos, la escuela, las casas de cultura y otros espacios de la comunidad. La integran graduados de las Escuelas de Instructores de Arte (2000) en las especialidades de Música, Teatro, Artes Plásticas y Danza. 
Aún me falta llegar a Maisí, para Los Días de la UNIMA ${ }^{13}$ en la Cruzada. Resulta muy pertinente desenvolver un espacio de reflexiones y troca de saberes donde se reconoce y desarrolla el protagonismo de los Títeres en la Cruzada. Maribel López, fundadora, directora durante muchos años, no se cansa de recordar el papel fundamental que tuvo para el desarrollo del repertorio del Guiñol Guantánamo, en función de la Cruzada, la asesoría de Armando Morales. Ya en los primeros años, él se encargó de revelar para Cuba y el mundo la Cruzada y lo hizo con amor crítico, con presencia ejemplar al decir:

La Cruzada Teatral Guantánamo-Baracoa es el evento teatral cubano en el que Revolución y Cultura materializan una ideología de alcance social amplio y abarcador que, pese a su trascendencia, no ha sido valorado en su justa extensión [...]. Mucho falta por hacer a las cruzadas... El propio cuerpo conceptual y teórico que sustentaría desde sus orígenes al proyecto, es decir, el trueque entre artistas y público ha quedado relegado a un segundo plano. Ese intercambio daría respuestas a los teatristas "que pudieran alimentar y reelaborar su lenguaje escénico, para entonces dirigirse a la comunidad a partir de sus valores autóctonos, escudos de identidad que le permitan enfrentar los vacíos y la uniformidad de los procesos civilizatorios al uso". Esa recopilación de vivencias, costumbres, proyecto de vida, narración oral, mitos y leyendas debieran constituir la fuente nutricia que les permita a los teatreros, comprometidos con la Cruzada, crecer y trascender sus propios límites de combate. (MORALES, 1997, p. 95)

Para culminar, el premio a la persistencia se alcanza en Baracoa con la Feria Teatral, en medio de todo eso deben cruzarse los diálogos abiertos, otra manera de invocar la producción de conocimiento sobre la Cruzada y en la Cruzada. Me hubiera gus-

13 Unión Internacional de Titiriteros o UNIMA, ONG con estatuto consultivo en la UNESCO. El día 20 de Mayo 1929 con ocasión del 5² Congreso de Marionetistas Checos, evento donde fueron invitadas personalidades de Bulgaria, Francia, Yugoslavia, Alemania, Austria, Rumania y la Unión Soviética, a propuesta del periodista y autor francés, Paul Jeanne, se establece en Praga la primera asociación internacional de teatro en el mundo. https://www.unima. org/es/unima/historia/ 
tado tanto poder participar este año en que el tema propuesto fue justamente: La mujer un universo de creación.

En la cruzadera, Cuba y el mundo se nos revelan. Este año confirmo mi intuición de inicios de los dosmiles cuando vaticinaba que los egresados de las escuelas de instructores de arte serían la vanguardia artística del siglo XXI. Allí están ellos, sin demeritar a los graduados de otras enseñanzas, están en los grupos demostrando la calidad de la formación que recibieron, danzan, tocan, cantan y oh casualidad, están allí cada año entre el mar y la montaña. Sin distinción de razas ni géneros van de la guaracha al bantú, de la zarzuela a la rumba; asumen sus derechos y deberes como artistas.

Y ya que viene al caso, de futuro quiero hablarle. Compadre Yosmel, visto que la Cruzada es un Acontecimiento cuya necesidad es perdurable y demostrada, por todos los beneficios con que a cada estrato de sus participantes alcanza: me atrevo a preguntarle en la confianza que el camión crea, ¿Cómo nos colocaremos de este aniversario en adelante?

La pregunta es aguda, por tanto pertinente. Pienso- con la humildad de quien poco ha subido, pero con el amor de quien admira y respeta- que entre las muchas acciones que se requieren para que se produzca el Acontecimiento ha de prepararse el relevo. Sí compay, hay un día en que la realidad nos avisa que nos pusimos grandes, es el día en que nuestros adultos no estarán más para girar la cabeza y preguntarles, es el día en que nos dicen: toca. Entonces, la trasmisión es hoy una condición para que se produzca el Acontecimiento. Ha de trasmitirse el valiosísimo patrimonio que es el conocimiento y la experiencia de cómo, por dónde, con quién, por qué, se organiza la Cruzada; incluyendo las relaciones, los lazos entre las generaciones y los promotores en las comunidades. Treinta años es una vida, por lo que pienso que la justa salvaguarda de la Cruzada requiere, hoy, de una organización planeada paulatinamente para el paso del bastón. Acompañar, compartir responsabilidades, asumir responsabilidades y delegar organizadamente me parece prudente y necesario. A fin de no aferrarse paternalistamente y mucho menos pecar de indolencia pueril: el futuro reclama de 
una transmisión de saberes en la práctica, cual aprendices, para recibir el poder de hacer acontecer. He aquí el ritual, el modo del traspaso: un viaje iniciático, una prueba, un saber y una memoria.

Y dirá que es mucho atrevimiento de mi parte viniendo de tan lejos. Yo le diré que es mínimamente el regalo de cumpleaños de una comadre cuya revelación consiste en haber comprendido, al cabo de los cuarenta y la curva donde se afila el Toa, que más allá de los títulos, los cargos, los premios y los contratos: hacer teatro, para mí, cobra sentido en la Plaza de Felicidad de Yateras. Cosa que París nunca me dará. Porque como ha dicho Martica Minipunto (2019), a quien tampoco le importa París: "Me importa Cuba. Me importa la vida de la gente en Cuba. Me importan mis muertos en Cuba".

En esa Cuba, treinta años de persistencia son indudablemente un Acontecimiento, una oportunidad revolucionaria, nacida justamente del instante imposible. Vienen tiempos duros. Para entonces, todo el patrimonio que restará será lo aprendido en el ritual de comulgar con la montaña. Acostumbran los pueblos a vigorizar sus luchas con la fuerza telúrica que se desprende al cavar el pasado para recuperar la memoria. Si hay proceso vivo hoy para Cuba y para el mundo, es la Cruzada. Viva ha de seguir de la mano de sus hijos, nietos, padrinos, entenados, abuelos, sus fundadores, como acto comunitario que es. Y para que así sea soy consciente del arduo trabajo organizativo que exige a lo largo de todo el año.

Ok compadre, llámeme pretenciosa. ¿Qué si me estoy creyendo la alcaldesa de San Nicolás para venir con eso? No es mi intención. Déjeme explicarme. Al borde de los cuarenta, el teatro -con todo el esfuerzo que reclama- no se hace más por vanidad, mucho menos por dinero; que ya sabemos que con mucho menos dolor se consigue más dinero haciendo otra cosa. Por eso, en la Cruzada no son posibles artificios ni afeites. La experiencia del Acontecimiento nos coloca frente al conócete a ti mismo y no hay otro teatro posible que el de la sinceridad. ¿Con quién, por qué hacer teatro? Conste que no es fácil. Hay que tener rigor y maestría para tener éxito en Bernardo de Yateras. 
La experiencia me atravesó la producción a lo largo de todo el año. Acabó pariéndome un teatro que traía atravesado y que se vuelve posible cuando no responde a más condición que el lance entre el público guantanamero y la honesta sencillez del creador.

Lo que quiero decirle compadre, es que, si la Cruzada le responde por qué hacer teatro, con quién hacer teatro, cómo es el teatro que lleva dentro; si por ese Acontecimiento, de las tripas nos nace teatro... hagamos juntos lo necesario para hacer acontecer. Pueden contar con nosotros.

¡Mis felicitaciones a todos los cruzados de estos treinta años! Un abrazo desde el Arca y hasta la próxima aventura. 


\section{REFERENCIAS}

BENJAMIN, Walter. Sobre el concepto de historia. In: Obras, I, 2, pp. 303-318, Traducción española de Alfredo Brotons Muñoz. Abada, Madrid, 2008. Disponible en: https://www. circulobellasartes.com/benjamin/obra.php?id=6

https://conversacionsobrehistoria.info/2018/09/23/walterbenjamin-sobre-el-concepto-de-historia-1940/. Consultado en: 5 nov. 2020

DOS SANTOS, Natália; NOLASCO, Edgar. Cultura local versus cultura global: o glocal. In: Raído. Dourados, UFGD, MS, v. 4, n. 7, p. 67-74, jan./jun. 2010. Disponible en: https://ojs.ufgd.edu.br/ index.php/Raido/article/view/590. Consultado en: 5 nov. 2020

KINCELER, José Luiz. Notas sobre o processo criativo da horta vertical saber. In: Arte no campo: perspectivas políticas e desafios. São Paulo: Outras expressões, 2016. p. 237-254.

LÓPEZ HAMZE, Isabel Cristina. Cruzada Teatral: una gran escuela en la montaña. In: El Caimán barbudo, sep. 10, 2019. Disponible en: https://medium.com/el-caim\%C3\%A1n-barbudo/cruzadateatral-una-gran-escuela-en-la-monta\%C3\%B1a-a16ff439c984. Consultado en: 17 abr. 2020.

LOURENÇO, Nelson. Globalização e glocalização. O difícil diálogo entre o global e o local. In: Mulemba 4 (8) | 2014. Disponible en: http://journals.openedition.org/mulemba/203; Consultado en: 16 feb. 2020.

MARTICA MINIPUNTO. París no me importa ni pinga. IN: PUCHEROS. hypermedia magazine, Noviembre 27, 2019. Disponible en: https://www.hypermediamagazine.com/ columnistas/pucheros/paris-no-me-importa-ni-pinga/. Consultado 16 feb. 2020.

MARTÍNEZ, Dairon. Amando la Cruzada teatral entre valles 
y montañas. In: Diario Digital Venceremos. Guantánamo, 5 de febrero de 2020. Disponible en: http://www.venceremos. cu/guantanamo-cultura-noticias/20134-amando-la-cruzadateatral-entre-valles-y-montanas. Consultado 15 feb. 2020.

MORALES, Armando. El sitio teatral a las montañas: acción de Quijotes. In: Tablas. La Habana, No. 1-2/ 1997. 